\title{
An Examination of Retail Product Return Behavior Based on Category of Good: An Abstract
}

\author{
Thomas L. Powers and Justin C. Lord
}

\begin{abstract}
A review of the literature indicates that product return behavior may differ by category of good due to a number of issues: product and emotional dissonance, the discovery of a better product or price, customer opportunism, awareness of return policies, and the timing of the return (Harris 2010; Kim and Wansink 2012). To address this gap in the literature, the purpose of this paper is to investigate how product return behavior may differ by category of goods across these issues. The research is based on a survey of 283 Target and Wal-Mart retail shoppers. The findings may help retailers manage and target product return policies to reduce financial losses and build stronger customer relationships (Berger et al. 2007; Ketzenberg and Zuidwijk 2009; Stamer and Diller 2006). There are several goods categories reported in the literature; however, the present research utilizes a commonly accepted categorization developed by Enis and Roering (1980) that classifies consumer goods as convenience, preference, shopping, or specialty. ANOVA was used to test for significant differences in these constructs across the different category of goods. The hypothesis for differences by product category for product dissonance (H1) was not supported $(F=0.69, p=0.557)$. Emotional dissonance $(\mathrm{H} 2)$ was supported as significant differences between category of goods were found $(F=6.28, p=0.000)$. Found better product $(\mathrm{H} 3)$ was supported $(F=5.77, p=0.001)$. Found better price $(\mathrm{H} 4)$ was not supported $(F=1.95, p=0.122)$. Customer opportunism (H5) was not supported $(F=0.97, p=0.409)$. Awareness of return policy (H6) was not supported $(F=0.07$, $p=0.978)$. Timing of return $(\mathrm{H} 7)$ was supported $(F=3.88, p=0.010)$. Product dissonance (H1) was predicted to vary across the category of goods but was found to be nonsignificant. This finding was surprising as it ran contrary to the existing literature indicating that variations of product attributes between categories of goods would influence dissonance. Return reason - found better price (H4) was predicted to vary across the category of goods but was also found to be nonsignificant. This is an interesting finding as the level of price and its associated perceived risk varies by product category. The research reported in this paper represents an initial investigation into the area of return behavior related to good categories.
\end{abstract}

T.L. Powers $(\bowtie) \bullet$ J.C. Lord

University of Alabama at Birmingham, Birmingham, AL, USA

e-mail: tpowers@uab.edu; jlord@uab.edu 